THURSDAY, OCTOBER 24, 1878

\section{THE CONSERVATION OF RIVERS}

$7 \mathrm{HE}$ question of the control of rivers has during the 1 last two years occupied more attention than had previously been bestowed upon it for a considerable period. The disastrous floods in South Wales and other parts of the country in the summer of I 875 caused a great outcry at the time, and this had hardly been forgotten when the evil recurred with still greater intensity, and in some cases more damaging effects in the winter of 1876-77. The immense amount of damage caused by floods in these two years, coupled with the fact that, in the opinion of a great many, they occurred at more frequent intervals than in former years, at length drew the attention of Government to the subject. Consequently in 1877 a Select Committee of the House of Lords was appointed to inquire into the operation of existing statutes in regard to the formation of, and proceedings by, Commissioners of Sewers, and Conservancy, Drainage, and River Navigation Boards; to consider by what means they could be more in expensively constituted and their powers enlarged so as to provide more efficiently for the storage of water and the prevention of floods. At the same time two other committees of the House of Commons were sitting on the same subject, but with reference only to the River Thames, one dealing with the question of the prevention of floods within the metropolitan district and the other within the whole valley of the Thames. A vast amount of information was collected from the numerous witnesses examined by these committees. Considerable difference of opinion was, as might be expected, found to exist in respect of the causes and best means of prevention of the severe floods experienced of late years in our different river basins, but by far the greater majority of the witnesses agreed that the floods were yearly getting worse than formerly, that the river channels were getting into a worse and worse state of neglect, and, what is a most important point in the practical bearing of the question, that the damage caused was so great that the carrying out of extensive remedial measures could in most instances be made to pay. It would appear at first sight a comparatively simple matter, given the drainage area of the river basin, the intensity and duration of the maximum observed rainfall, and the hydraulic inclination of the river, to calculate the sectional area of channel requisite for the maximum discharge; this is doubtless the case, but unfortunately in the early history of the world the formation of rivers was left entirely to the forces of nature without the professional assistance of a competent engineer. If an engineer of suitable experience were called upon to design a river from source to the sea, he could doubtless successfully accomplish the work, but the problem the legislature is now called upon to deal with is of far greater complexity. Not only have the rivers themselves been doing all they could to make things difficult, meandering in graceful curves through plains where they ought to have gone in straight lines, and silting up where greater depth of channel was necessary, but the inhabitants of the

VoL. XVIII.-No. 469 country most interested have followed the same course now for some centuries by constituting themselves under Acts of Parliament into innumerable small drainage boards with certain definite powers within their own districts, but unable and unwilling to join together and act for their general good.

The Select Committee on the Prevention of Floods within the Metropolitan District had a comparatively simple question to deal with. Accurate and long-continued observations on the levels of high water were produced, showing the result of the various works of improvement that have been carried out since it was decided to remove old London Bridge. The tides in the Thames are the resultant of two tidal waves, one reaching the mouth of the river by the North Sea, the other by the English Channel, the former arriving at the river usually about three hours before the latter. But certain conditions of the wind on some occasions bring these two tidal waves together; thus a south-westerly gale accelerates the English Channel wave and retards the North Sea wave, while again the latter may be increased by a north-west wind off the coast of Scotland blowing at the same time. The highest tide on record in the Thames was that of November $\times 5$, 1875, which rose to the height of 4 feet 7 inches above Trinity high-water, or 3 feet 2 inches above the predicted height; that of January 2, 1877, exceeded the predicted height by 3 feet 4 inches, and reached a height of 4 feet above Trinity high-water. The conditions producing these results were nearly the same: in the south a southwesterly gale, in the north a north-westerly with an easterly wind blowing up the Thames, combined with a low barometric pressure over the river valley and continued heavy rains. Almost the worst possible concurrence of circumstances having on previous occasions occurred, it will not be too much to predict their recurrence at some future time, and possibly with much more disastrous effects ; for whereas the highest tide on record, that on November 15, 1875, was only 3 feet 2 inches above its calculated height, that of December I2, I 845 , rose to 5 feet 7 inches above its predicted height, showing that a suitable concurrence of conditions might produce a tidal wave upwards of 2 feet at least above the higbest on record. In the face of these facts and the repeated inundations of low-lying parts of the metropolis, it is simply astounding that so little should be done not only to obviate the recurrence of a well-known evil, but to prevent a much worse one from happening. Bearing in mind the great and costly works carried out by the Metropolitan Board of Works in the main drainage of London, the Thames embankments and the numerous new streets, and, finally, also in their last great work of buying up and freeing the bridges, it would appear a small thing to raise the height of the river banks at the few places necessary to prevent the periodical inundations; but though there is no difference of opinion as to the character and extent of the works required, the Select Committee and the Board do not seem to have agreed on the question of how the improvements are to be paid for, and the matter appears again to have gone to sleep.

The general question of the control of the entire river channels is one of much greater complexity than the prevention of the periodic overflows of the Thames. 
in the Metropolitan District. It was, therefore, with great in the President of the $\mathrm{Me}$ pleasure that Section of the British Association, Mr. Edward Easton, did so much to further the consideration of the question by making it the subject of his opening address at the recent Dublin meeting, and the number of papers by various well-known authorities that followed on the different branches of the same subject, with the discussions thereon, still more enhanced its value. The scope of the whole question involves, as well as the prevention of floods, the following considerations, as pointed out by the President:-the supply of pure and wholesome water for domestic and sanitary wants, the supply of water of proper quality and sufficient quantity for industrial purposes, the proper development of water power, land drainage, and irrigation, navigation, and the preservation of fish. It has long been found in most districts that many of these interests are mutually antagonistic, that the use of water for manufacturing purposes and sanitary arrangements interferes with the supply of pure water for domestic purposes in the places lower down the stream; that the utilisation of water-power by the erection of milldams and weirs impedes the passage of floods and renders efficient land drainage more difficult, while on most navigable rivers the navigation and drainage interests seem to be constantly in opposition. Before two of the Select Committees referred to much useful information was given by the different witnesses examined, but the absence of discussion left much useful work to be done at the Mechanical Section at Dublin.

The facts most prominently brought forward and the remedies advocated may now be considered. The passage to the sea of the water falling as rain may not only be too much retarded, causing loss to the producing power of the country by submerging large tracts of valuable land for a long period; but it may easily be too much accelerated, causing great loss and inconvenience from drought in summer. Notwithstanding the persistence of rainy weather, so much complained of in our climate, most of our rivers would sink to most insignificant dimensions were not some provision made for impounding the water in times of drought. In the fen country admirable provision for floods was made by the early Dutch engineers employed, who, finding the natural river channels, though adapted for the ordinary flow, quite incapable of containing the flood waters, raised banks a considerable distance back from the natural bed of the river. Long tracts of country were thus inclosed and formed into a channel for the passage of flood waters; and, had the works been completed to the outfalls of the river, or had those outfalls been artificially deepened and straightened in those days to the extent they have since, there is little doubt that the result would have been completely satisfactory. As it is, with the extension of works at the outfall of the rivers, rendered necessary by increasing quantity and size of shipping, the original works have been allowed to fall into decay, or have been so altered by the erection of dams and sluices as no longer to fulfil their original uses. What is required in these rivers, then, is to a great extent merely to restore them to the state they were in when left by their original improvers, continuing the improvement of the outfalls, and removing the shoals and other obstructions that have grown up since that time. To remove the whole of the weirs and sluices would be to take away almost the entire water supply, in time of drought, for agricultural purposes. The weirs will therefore have to be made movable, rendering it an easy matter to retain the water supply in summer, while, by lifting the sluices in good time, on the approach of floods, the channel will be freed of all obstructions. In the case of all the rivers considered--the Thames, the Severn, the Shannon, the Great Ouse, Nene, Witham, and others-it was shown that the channels had been suffering continued deterioration from the formation of shoals and the growth of weeds, and that the dams and weirs erected for the maintenance of the water-level in dry weather were not provided with sufficient sectional area for the flood discharge. The engineering difficulties in the way of a complete improvement of our principal rivers are not at all insurmountable, but the legislation necessary has proved abortive. Each river basin is cut up into a number of drainage districts, formed under Acts of Parliament obtained at various times, and wholly without reference to each other. One district is unable to obtain powers to make improvements in its portion of the river without encountering a determined opposition from the districts.below, who find that their works would be imperilled by the alterations; and thus a great proportion of the cost of any improvements is spent in parliamentary contests. There is now an almost general agreement in the opinion that the difficulties in the management of rivers are due to divided authority, and that the question could be satisfactorily dealt with if entire river-basins were placed under the control of one body of conservators. The conclusion arrived at is that each river-basin must be placed under the care of a single Conservancy Board, who shall have to decide on and execute any general scheme for the improvement of the river; that this Board shall consist of members chosen from the various districts Boards, which would have the power of executing minor works in their own districts, not affecting the general régime of the river, but subject at all times to the control of the combined Board; that the powers of rating conferred on the combined Board shall extend over the whole river basins, but that a special'additional rate shall be levied on those districts most directly benefited by the improvements.

It has been proposed, also, that a Central Board should be established in the metropolis, presided over by a Cabinet Minister, to which appeal from the decisions of the various Conservancy Boards can be made, and that this Central Board shall have powers analogous to the Local Government Board, of issuing provisional orders, to be subsequently confirmed by Act of Parliament, thus greatly diminishing the cost to the local ratepayers of the improvements they desire. At the conclusion of the Dublin meeting a recommendation was made by the Mechanical Section that a Committee of the British Association should be appointed to ascertain what steps should be urged on Government to bring about the undivided control of river basins in this country. As it appears very uncertain what action Government may take on the Reports of the Select Committees of 
both Houses on this question, the Council of the British Association may be able to do a work of great national importance by pointing out clearly and definitely what must be done, and by the publication of an annual report on the progress made preventing the subject again being allowed to drop.

\section{STELLAR OBJECTS SEEN DURING THE ECLIPSE OF 1869}

$\mathrm{T}$ will be remembered by the reader who has interested 1 himself in the published reports of observations of recent total eclipses of the sun, that during the totality on August 7, 1869, at a point in Iowa, called St. Paul's Junction, several observers attached to a party organised by Mr. W. S. Gilman, of New York, remarked below the sun what they termed "a little brilliant," and that one of the number using a small telescope, reported baving seen just before the sun disappeared and as he came out again a minute crescent, in a similar direction from the moon. Commodore Sands, then Superintendent of the Naval Observatory, Washington, expressed his regret that these objects should not have been seen by Mr. Gilman himself, who had experience of the use of the telescope and was using a larger instrument than the others who had optical aid-but"his "plan of operations" did not permit of it. The facts are thus stated :-A few moments after the corona formed, a small but exceedingly bright point, like a star, was noted independently by four of the party, two of whom it is mentioned were observing without telescopes; it appeared near the limits of the corona, below the moon's disc, and with one exception the observers located it a little to the right of an "anvil-shaped" prominence, or "at about $230^{\circ}$ from the north point, reckoning by the east," and it is added that each of the observers felt quite positive that what he saw was truly a star. With respect to the small crescent Mr. Gilman reports that about half a minute preceding totality another member of the party, Mr. Vincent, came to him exclaiming that he saw a miniature-crescent-shaped star under the moon, and asking him to verify the observation, but, interested in his own work, he did not at the moment do so; on $\mathrm{Mr}$. Vincent returning more urgent than ever, Mr. Gilman says he did look in a hurried manner but saw nothing in the few seconds he gave to the search; he afterwards states, however, that he does not think he looked so far away from the moon as the crescent was located in a drawing made immediately after the eclipse by Mr. Vincent; in this drawing it was placed "at one and a half times the moon's diameter from its limb, and to the left of a perpendicular down to the horizon." $\mathrm{Mr}$. Gilman adds he could not connect this crescent with the small star of the other observers, indeed Mr. Vincent estimated the object seen by him at three times as far removed from the moon's limb as the small star, which would assign for the latter a distance of about half a degree, corresponding very well to the expression used by the four observers who noted it, that it was near the limits of the corona. Dr. B. A. Gould, now Director of the Observatory at Cordoba, who observed this eclipse at a different station, gave some attention to a search for any object near the sun which might be in intra-Mercurial planet, and he states he saw the star $\pi$ Cancri, but did not meet with any other stellar body. This star being at the time in a similar direction from the moon's centre, to "the little brilliant" of the Iowa observers, there has been a pretty general opinion that it was the object remarked by them, and, in conversation with Dr. Gould several years since, I found him tolerably well satisfied that he had thus sufficiently explained their observations. But the discovery, or rather discoveries, of Prof. Watson, lend a new interest to them, and a more strict examination of the circumstances may not be out of place here. The position of St. Paul's Junction is stated to be in latitude $42^{\circ} 47^{\prime} 30^{\prime \prime} \mathrm{N}$., and longitude $19^{\circ} 5^{\prime} 45^{\prime \prime} \mathrm{W}$. of Washington. The totality was observed to commence at $5 \mathrm{~h} .48 \mathrm{~m} .46 \mathrm{~s}$, ending at $5 \mathrm{~h}$. $5 \mathrm{Im} .34 \mathrm{~s}$. M.T. at Washington, so that the middle occurred at $10 \mathrm{~h} .58 \mathrm{~m} .22 \mathrm{~s}$. M.T. at Greenwich, which agrees exactly with a calculation made with the Nautical Almanac elements. We will assume 10 . 59m. G.M.T. as the time to which the observations of the brilliant point apply. Correcting the moon's place for the effect of parallax, we find her apparent position at this time to be in right ascension, 9h. IIm. 26.7s., and north declination $16^{\circ} 13^{\prime} 58^{\prime \prime}$; her augmented semi-diameter was $16^{\prime} 37^{\prime \prime}$. We must assume that both star-like object and crescent were on an angle of $230^{\circ}$, the latter one. and-a-half times the moon's diameter from her limb, and the former at one-third of this distance, whence, referring to the moon's centre, we have, for the crescent, $\Delta a=$ $-3 \mathrm{~m} .32 \mathrm{~s}, \Delta \delta=-42^{\prime} \cdot 7$, and for the bright little star, $\Delta a=-\mathrm{Im} .46 \mathrm{~s} ., \Delta \delta=-2 \mathrm{I}^{\prime \prime} 4$; and thus,

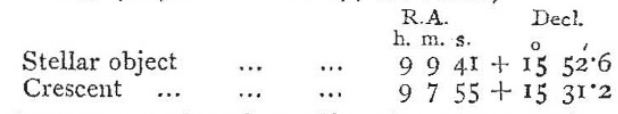

The former was therefore $28^{\prime}$ and the latter $56^{\prime}$ south of the ecliptic.

Now with regard to the star, the presence of which has been supposed to explain the observation of the four observers who noted "the little brilliant," there has been some slight confusion. In a note inserted in the last "Annual Report" of the Royal Astronomical Society it is stated that the object seen "has been satisfactorily identified as the star $\pi^{1}$ Cancri," which is assuredly a mistake. $\pi^{\mathfrak{i}}$, according to Argelander, is only a seventh magnitude, which is hardly to be glimpsed with the most acute sight in the darkest winter sky. For $\pi^{1}$ no doubt we must read $\pi^{2}$, or 82 Cancri. But this star, also, is of a degree of brightness wholly insufficient to allow of it being possible to discern it at all so near the sun's place without some optical aid in the still illuminated sky-ground, much less to be caught up as a brilliant point of light, with the naked eye ; the "Durchmusterung" estimate is $5.8 \mathrm{~m}$., which is confirmed by the careful estimations of the second Radcliffe Catalogue, where we find it rated $5.9 \mathrm{~m}$., or, in round magnitudes, a sixth. It should be mentioned that the apparent place of 82 Cancri was in right ascension 9h. 7m. 59.5s., declination $15^{\circ} 28^{\prime} 56^{\prime \prime}$, agreeing nearly with that we have found for the minute crescent, but $33^{\prime}$ from the small star. It appears probable, in view of Prof. Watson's discovery, that Dr. Gould may have mistaken an intra-Mercurial planet for $\pi^{2}$ Cancri, and if the statements of the four observers at St. Paul's Junction (one of them, by the way, a lady) are accepted, it can hardly be doubted that they also were 